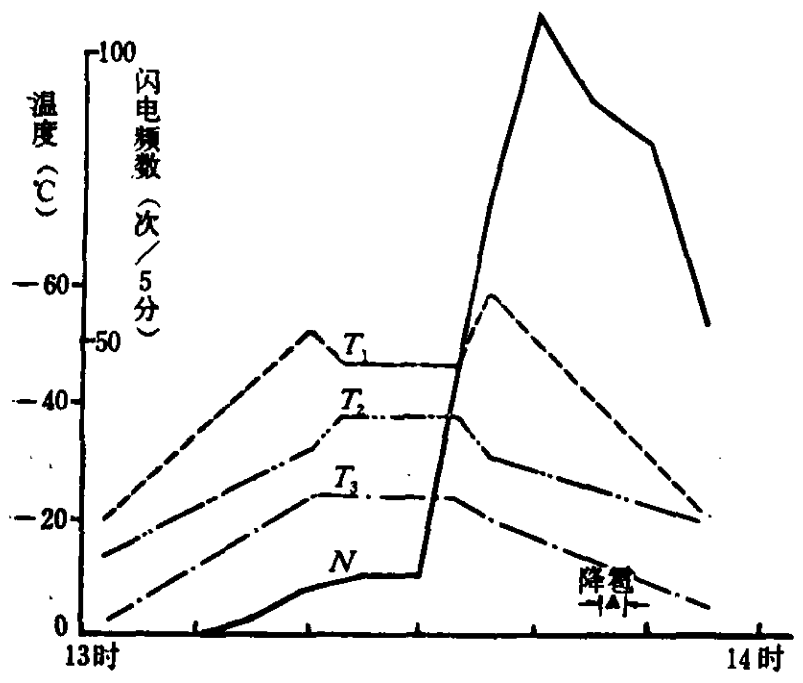

图 51973 年 8 月 8 日冰雹云回波顶温 度和闪电频数的时间演变图 (昔阳地区)

自然成冰区 $\left(-20^{\circ} \mathrm{C}\right.$ 以下 $)$ 之后出现和加强 的. 特别是云中含水量高的强回波区（即衰 减值大区)，作用更显著．可以注意到，当 $T_{1}$ 跨入自然成冰区后 10 分钟, 开始出现闪电活 动, 但闪电的跃增却是在当 $T_{3}$ 跨入自然成冰 区后 10 余分钟发生的. 由此可见,云中水化 过程是闪电活动的先驱, 也就是说成雹过程 促进了闪电活动加剧. 与上述过程相反, 13
时 36 分以后, 各种顶温升高, 却导致了几分 钟后闪电活动的减少; 13 时 40 分以后云中 开始的降雹过程则不但使云体削弱，也导致 了闪电活动急骤减少，当 13 时 46 分地面见 霖之后, 闪电频数开始陡降. 由此可见, 回波 区的冰化过程 (也就是冰䨞形成过程)很大程 度上影响了云中闪电活动, 云中水成物的冰 化过程是闪电重要成因之一。由此可见，用 云中闪电特征来识别冰霓云是可行办法的道 理也就在这里.

\section{參考资 料}

[1] 王昂生、黄美元、物理 $1975,4,1,14-20$.

[2] 甘肃省气象局研究所,气象, $1975,7,11-12$.

[ 3 ] Сулаквелидзе Г. К., Ливневые Осадка и Град, Гидрометеоиздат, Л., 1967.

[4] Eccles, P. J. and Atlas, D., 14th Radar Meteorology Conference, AMS, 1970, 1-6.

[ 5 ] Baughman, R. G. and Fuaquay, D. M., J. Appl. Met., 9 (1970), 4, 655-660.

[6] Blevine, L. L. and Marwitz, J. D., Weather, 1968, 192-194.

[7] Smith, M. D., Proc. Intter. Cont. on Clout Physics, 1968, Toronto. Canada, 460-463.

\title{
某些神经药物对针刺抑制内脏一一躯体反射效应的影响
}

\author{
许冠蒜 郑观成“沈 锣 \\ （上海生理研究所）
}

过去，我们证实在电针抑制猫内肚一躯 体反射效应中必须有脊髓以上脑结构的下行 抑制参与 ${ }^{[1]}$. 接着、我们损毁脑的各个部分, 看到损毁延脑中央部分可大部取消这种电针 抑制效应 ${ }^{[2]}$ ，推测延脑部分的中缝核群可能 是这种下行抑制的主要起源。中缝核群是以 5-羟色胺为递质的神经元细胞体密集的地 方. 在本工作中,我们运用某些药理方法检验 5-埥色胺在这种电针抑制效应中作为神经递 质的可能性.
用 33 只成年猫作实验. 在乙醚麻醉下 手术, 手术后用三碘季胺酚麻痹, 给予人工呼 吸. 用波宽 0.1 毫秒方波刺激内胜大神经, 强度 5-8 伏, 在第 11 肋间神经引导反射放 电. 在下肢阳陵泉、阳关二穴进针并通电, 电针 用连续方波,波宽 0.1 毫秒, 频率 100 次/秒, 强度 $1-2$ 伏.

用阻断5一羟色胺生物合成的药物对氯苯

本文 1976 年 4 月 12 日收到。

* 现在第四军医大学生理教研组. 
丙氨酸 (pCPA) 甲脂 3 毫克 (溶于 70 微升生 理盐水中, $\mathrm{pH}$ 6) 作侧脑室注射. 注射后自 发放电增加. 5 只猫中有 3 只在注射后 $1-3$ 小时内脏一躯体反射“释放”(反应增大, 表示 紧张性下行抑制部分地解除 $\left.{ }^{[1]}\right)$, 在电针期间 仍能基本上被抑制, 但较注药前略差, 电针后 抑制效应更差些. $\mathrm{pCPA}$ 一般为腹腔注射, 作 用缓慢. 经侧脑室给药可能作用稍快些, 但 尚末见到侧脑室给药后数小时内的脑内5-差 色胺含量分析的报道. 我们在急性实验中看 到以上这些影响, 仅能给我们一种提示, 即 5-䍩色胺在这种电针效应中可能是重要的.

在 13 只动物侧脑室注射 5-差色胺 200-300 微克, 对电针抑制效应的影响一般 不明显, 但如减弱电针强度, 使抑制不完全, 则给 5-埥色胺可增强电针抑制效应. 图 1 为 其中用弱电针的 5 只动物的结果，注药后 5 分钟 (即图中 15 分钟时) 和侧脑室注射等容

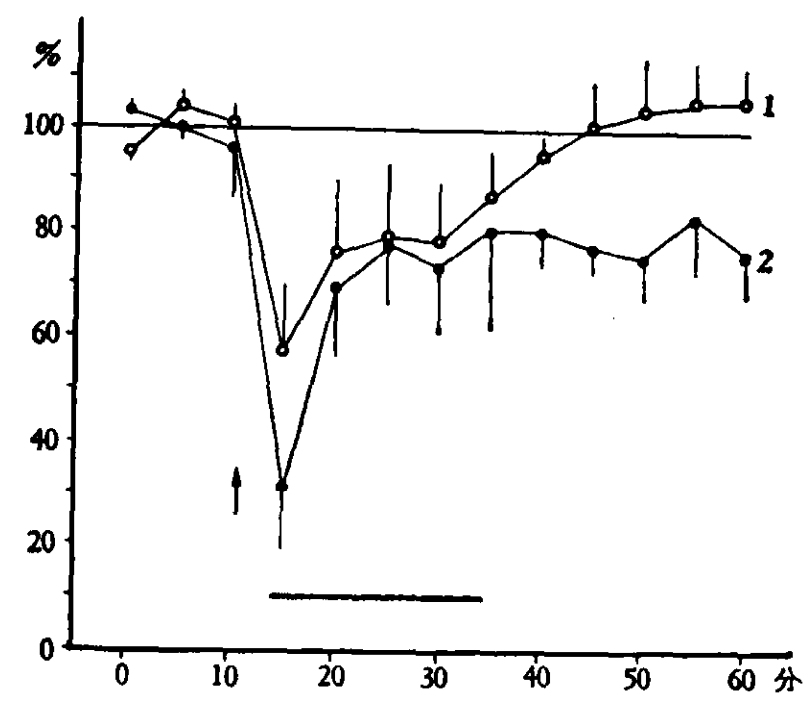

图 1 侧脑室注射 5-埥色胺对电针抑制效 应的影响

1. 圆国为注射生理盐水加电针的系列 $(n=5)$;

2. 圆点为注射5-鞚色胺加电针的系列 $(n=5)$.

图下方栱线为给电针的时间，箭头为侧脑空 注射 5- 筇色胺或等容量生理盐水的时间.

在每次实验中, 以连续 3 次反应的平均值代 表每一时间的反应愊度, 然后 5 次实验平均, 得出 图中各点, 各点均以相当于电针前的反应平均值 的百分比计算. 各点上的垂直线为标准误. 横座 标为时间(分)
量生理盐水的电针效应相比, 有显著差异、 $p<0.05$, 注药的电针后效应也较注射生理 盐水的为强, 但经统计学处理, 差异不够显 著。

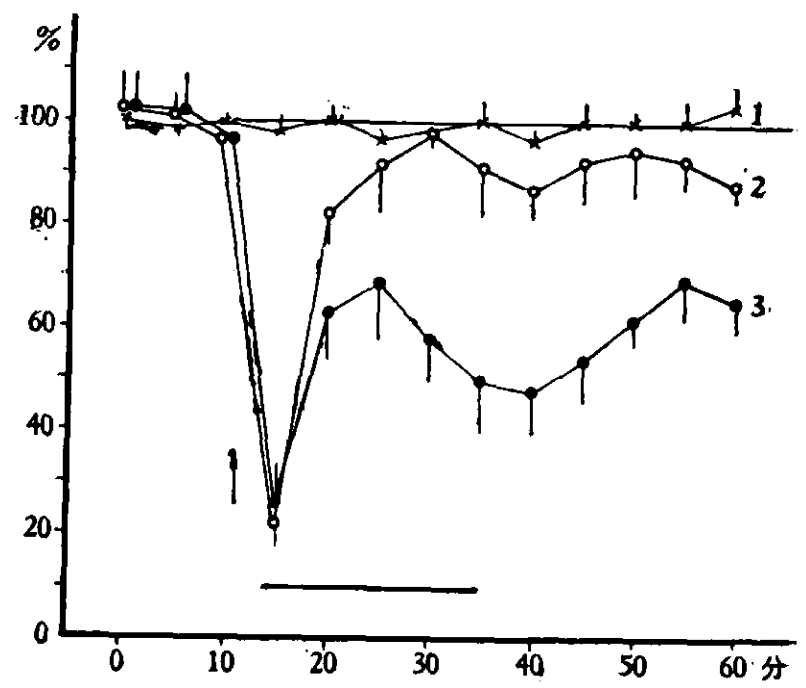

图 2 静脉注射 LSD 对电针抑制效应的影响 1. $\times$ 号代表内脏一躯体反射在长时间内的波动 $(n=9)$;

2. 圆图为注药前的电针系列 $(n=10)$;

3. 圆点为注射 LSD 加上电针的系列 $(n=10)$.

下方横线为给电针的时间, 箭头为注射 LSD 的时间。

图中各点分别为 9 次 (1) 及 10 次 (2.3) 实验 的平均值，计算方法同图 2. 横座标为时间(分)

在 10 只动物身上静脉注射麦角酰胺 (LSD) 100 微克/公斤, 在图 2 中可看到注药. 后电针的后效应明显增强, 图中 35-50 分钟 各点注药后和不注药的电针效应比较均有明: 显差异 $(p<0.05)$. LSD 和 5-羟色胺在外周 (平滑肌) 的作用是相对抗的, 但在中枢神经 系统，有人认为 LSD 可以兴奋 5-羟色胺受 体 ${ }^{[3]}$,因而可以模拟 5 -羟色胺的作用.

以上实验表明, 5-羟色胺可能是参与这 种电针抑制效应的神经递质.

\section{参考资料}

[1] 沈镖等,中华医学杂志, 54(1974), 628-633.

[2] 杜族基等,中国科学, 18(1975), 631-639.

[3] Anden, N. E. et al., Brit. J. Pharmacol, 34 (1968), 1-7. 